\title{
Tree-Trunk Apartment
}

\author{
By Cy Hampson, Edmonton, Alberta
}

(with photos by the author)

\begin{abstract}
"Can't you do something about that dripping tap?"

I struggled valiantly to enter the world of consciousness but slipped under again.
\end{abstract}

"Here's the wrench. It's driving me crazy." This time, I crossed the threshold and suddenly bec a m e aware of my wife standing over me in her dressing gown and brandishing a pipe wrench in her right hand.

"Please," she exhorted, "go down and fix that leaky tap. I've been trying for hours and hours to get to sleep." I struggled into the sweater which she was holding, absently took the pipe wrench from her hand and made my way obediently in the direction of the kitchen. Yawning, I switched on the light and began methodically to spread the jaws of the wrench. I squinted at the hot tap marked "Cold" but it yielded nothing. I had suspected this one; this was ever its favourite hour of performance. The cold-water tap with its legend "Hot" proved equally dry so I headed for the bathroom. No dice-both as dry as the shifting, shimmering sands of the Sahara. Concluding that I must be the only drip in the house, I deposited the wrench angrily upon the bedside rug and-crawled in again beside my wife.

I had just begun to doze again when Clara shook me violently. "If you don't go down and fix that tap right now, I'll phone the plumbers .... or the Fire Department ... or the Police Station!"

This time, I struggled into a sitting position and began to explain as evenly as I could at $3: 30$ in the morning: "The taps are all tight. Every single one of them."

"Well, you're as deaf as a dead horse if you can't hear that tap dripping right now," she retorted. "Just listen."

And suddenly I heard it. The clear, piping call of the little saw-whet owl coming up from the ravine back of the house. Only on occasions such as this had I grave doubts about the advisability of a would-be ornithologist marrying a defenceless stenographer.

"That's our saw-whet again. Remember. We heard him last year about this time. They nested in the apartment in the old dead poplar that blew down late this winter. They brought off the five youngsters we photographed out on the branch."

"But I didn't know that owls pecked holes in trees."

"They don't," I answered. "A woodpecker pecked out the cavity originally. The owls took it over later."

The tree in question had housed many interesting folk throughout much of its life and at least part of its death. It had first come to my attention a dozen years earlier when it still boasted a living branch or two, each equipped with a few life-preserving leaves. At this time, a pair of flickers had earnestly and exuberantly pecked out a cavity in

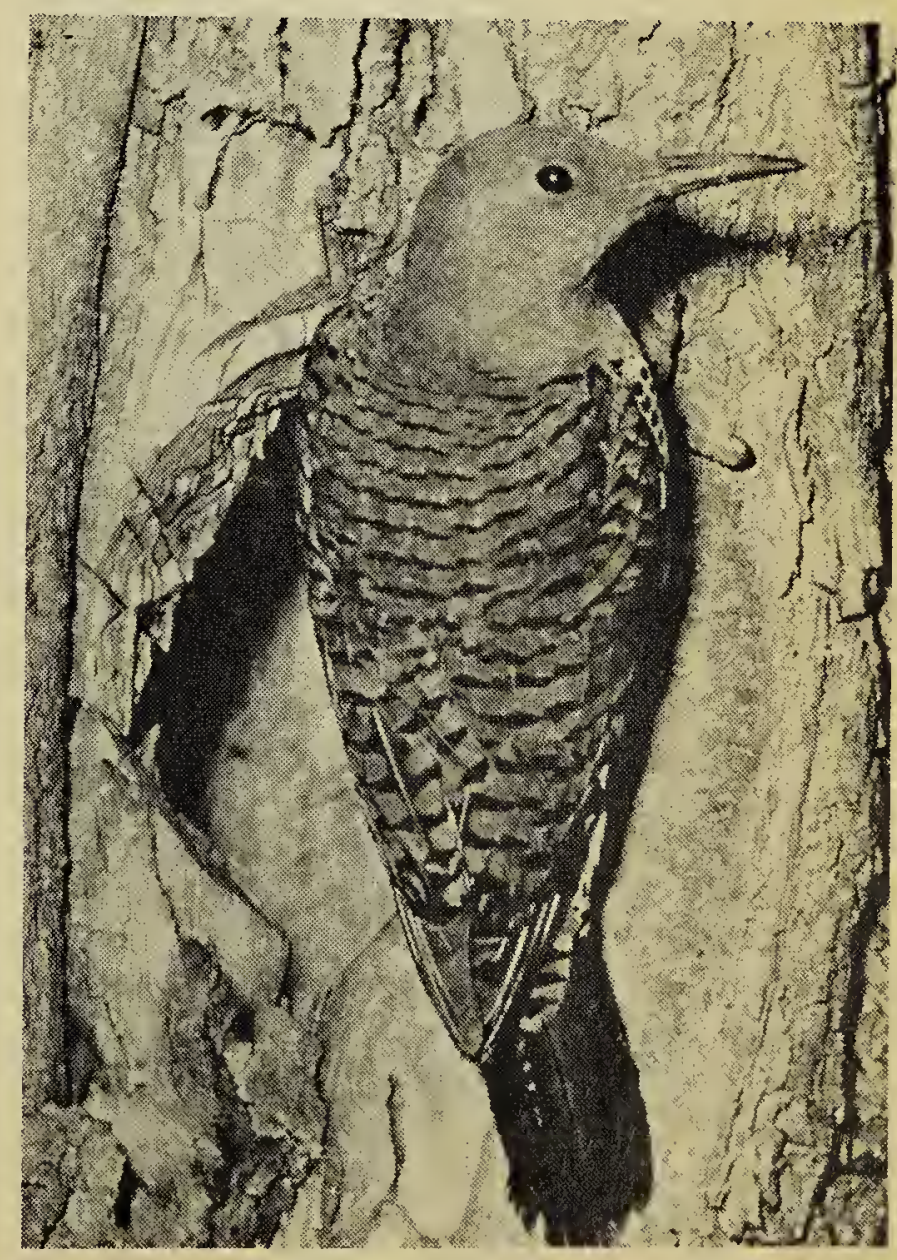

Original tenants of the tree-trunk apartment "a pair of flickers reared their buzzing brood." 


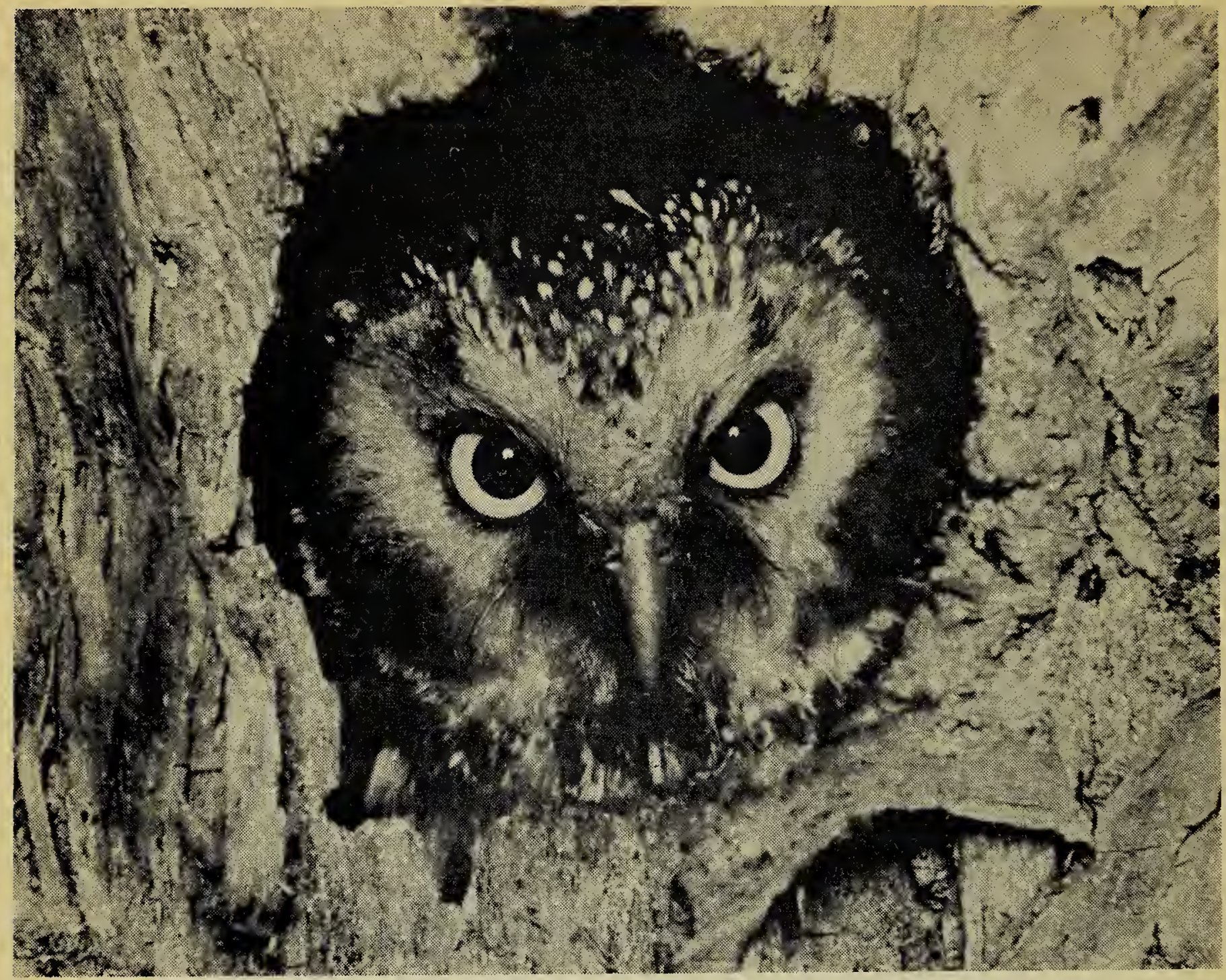

Second tenant- "perhaps our rarest visitor to the ravine"- the Richardson's Owl.

which they reared their buzzing brood. With great interest, we had watched the parents insert their stilletto-like beaks deep down the throats of the gaping youngsters in order to feed them.

Then a couple of years passed during which the apartment remained vacant and visibly "To Let." Early one March we recorded perhaps our rarest visitors to the ravine, a pair of Richardson's owls. The soft, musical notes of this small owl, drifting up from the spruce in the evenings, were quite unlike those of the even more diminutive saw-whet. The series of notes rose slightly in pitch and were much more closely spaced than those of the latter. Unless this owl has two quite different songs, I am convinced that Seton's notes referring to the species on the banks of the Athabaska River must, in reality, refer to the spring song of the saw-whet. The Richardson's owls at length took over the "flat" and nested there. They must have found both the entrance and quarters somewhat restricted in size; I had only previously known them to nest in the deserted nesting sites of the great pileated woodpecker.

The tree had long since been dead and dilapidated when the saw-whets discovered its possibilities. For two years hand-running a pair of them occupied the cavity, filling the long spring nights with their delightful, measured, bell-like notes. We soon learned that we could bring them to within a few yards of us by standing in the deep shadows of the spruce trees and imitating their calls by whistling.

Indeed, a friend, Eddie Jones, captured one of these tiny owls by hand one warm April night when we were out whistling them in. The bird had come progressively closer until it perched directly above his head and less than ten feet away. As Eddie continued whistling, the owl suddenly left its perch and dropped directly upon his up-turned face. Eddie was so startled that he involuntarily brushed the bird to the ground at his feet. To our utter amazement, the owl immediately 


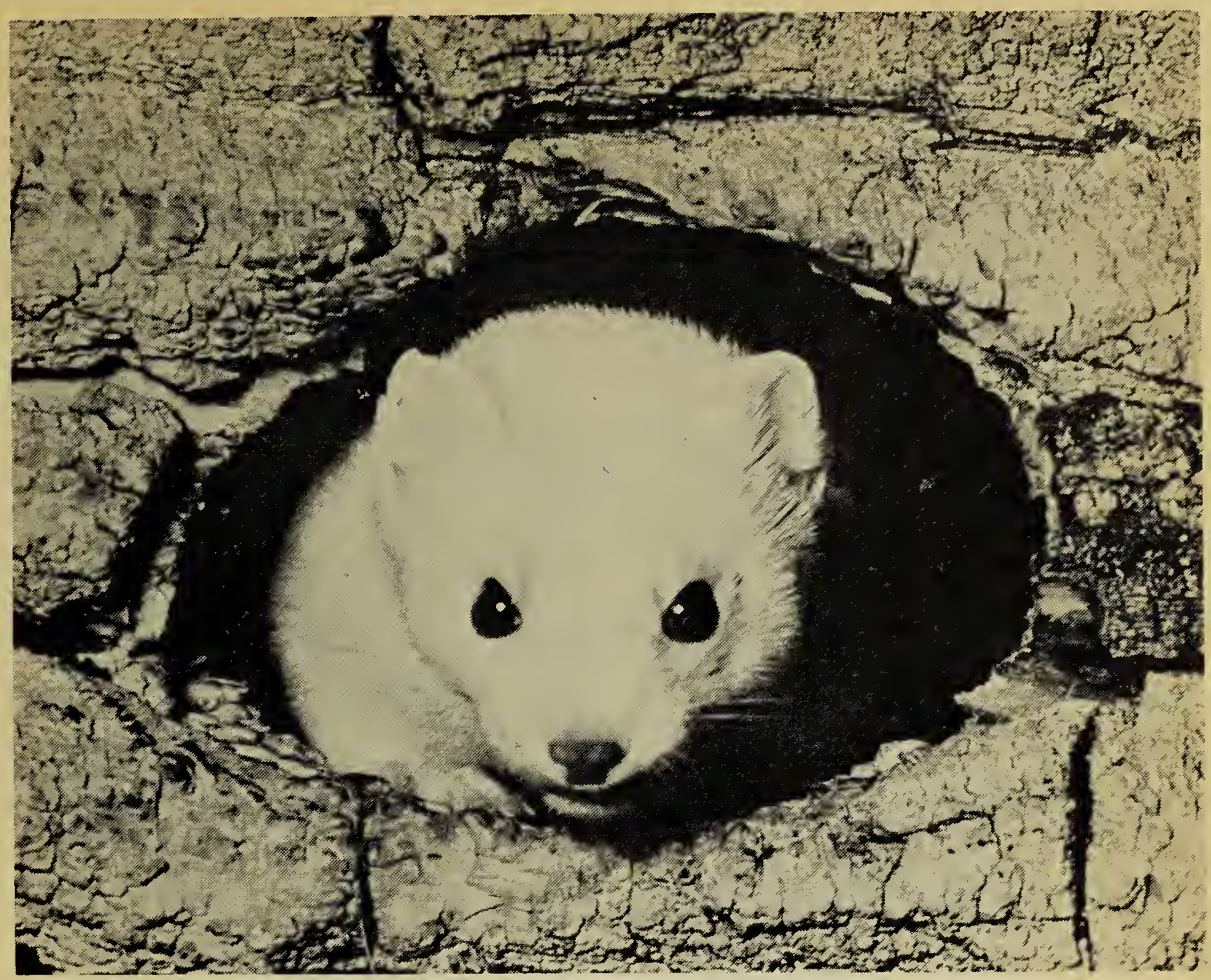

Final tenant, the weasel- "A white animated face made its appearance."

flew up to another tree nearby and began once again to pipe. The original performance was repeated almost exactly except that on the second occasion Eddie was ready with his hands cupped about his face. As the owl landed, he deftly closed his hands and caught it. We banded the bird immediately and released it. None the worse, the pair brought off their brood successfully.

The next winter, a heavy January gale had brought the great, shallowrooted tree to the ground, breaking it into two séctions as it fell. This, we felt, must surely be the end of its tenancy by birds. And so it proved. However, one day in early February I had been tramping up the ravine with binoculars and camera when I came upon the paired tracks of a weasel in the new-fallen snow. I followed them curiously and judged from the intervening spaces when the animal had crossed clearings that it must be the long-tailed species. The trail led by devious route to the fallen tree-indeed, to the very cavity which the saw- whets had tenanted the spring before. The trail led in but not out.

As I puzzled momentarily, a white animated face with black lustrous eyes and prominent ears made its appearance at the entrance. Quickly advancing, I drove the weasel back inside and hastily set up my camera. He re-appeared in a moment or two and I photographed, in all probability, the last tenant of this, our tree-trunk apartment.

This "Story for Professors" was sent to us by a reader who enjoys Punch:

Query in Scottish Farmer:

Do swans fly across country? If so, how far?

Answer: Yes. The distance depends on where they are going.

Punch comments: For long journeys, of course, they start farther back. 